\title{
TEXTURES OF PARAGNEISSES FROM THE KTB DRILLING SITE, NE BAVARIA (FRG)
}

\author{
F. HEINICKE, H.-G. BROKMEIER and M. DAHMS
}

GKSS Research Center, Max Planck Str., D-2054 Geesthacht, FRG

\section{H. J. BUNGE}

Department of Physical Metallurgy, Technical University Clausthal,

D-3392 Clausthal-Z., FRG

J. PANNETIER and C. RITTER

Institut Laue-Langevin, 156X, F-38042 Grenoble Cèdex, France

H. DE WALL

IGDL, Univ. Gơttingen, Goldschmidtstr. 3, D-3400 Gorttingen, FRG

From September 1987 to April 1989 a pilot boring for the German Continental Deep Drilling Project (KTB) was made about $80 \mathrm{~km}$ east of Bayreuth, NE Bavaria (FRG). The final depth of the drill hole was $4000 \mathrm{~m}(1)$. The drilling site is situated at the western margin of the Bohemian Massif, an area of crystalline rocks which has been deformed frequently during a time span of several hundret millions of years. The rock sequence found in the borehole belongs completely to a geologic nappe (named ZEV), which is thought to has moved to its actual position during a late phase of the variscan deformation ( $330 \mathrm{Ma}$ ago). Its deformation is significantly distinct from that found in the surrounding 'allochthonous' units(2).

The rocks of the ZEV are mostly paragneisses and amphibolites of variable compositions. Several paragneiss samples were choosen for textural investigations from the drilled cores. This contribution is restricted to the texture analysis of one specimen, further results are presented elsewhere $(3,4)$.

\section{SAMPLE DESCRIPTION}

Specimen $71 \mathrm{B5b}$ (depth $470 \mathrm{~m}$ ) is subject of the texture analysis presented here. This specimen is typical for the oldest deformation found within the paragneisses. It contains the mineral cyanite which indicates a deformation typical for the $\mathrm{ZEV}$ at $\mathrm{P}=6-8 \mathrm{kbar}, \mathrm{T}=650-750^{\circ} \mathrm{C}, 390 \mathrm{my}$ ago(2). The diaphtoritic reactions(5) which are common in the paragneisses are weakly developed, so most of the biotite and oligoclase is preserved. The mineralogical composition is roughly: quartz (45\%), oligoclase $(30 \%)$, biotite $(10 \%)$, muscovite, cyanite + sillimanite, garnet. 
Some ribbon quartz is developed and there are no recrystallized grains at grain boundaries (in contrast to other specimens). Macroscopically, the sample is dark with some light bands (quartz + oligoclase). The foliation is well developed due to the separation of biotite which is significant especially in the section parallel to the lineation (XZ-section, cf. fig.1).

\section{EXPERIMENTAL}

The texture measurements were carried out at ILL, Grenoble, using intrument D1B. The D1B instrument offers an $3 \mathrm{He}$-filled $80^{\circ}$ bananatype detector with an angular resolution of $0.2^{\circ}$. A monochromatic neutron beam with $\lambda=2.5237 \AA$ was produced by a graphite-002 monochromator.

For the measuring procedure a small cylinder $(9 \mathrm{~mm}$ in length, $18 \mathrm{~mm}$ in diameter) has been prepared from the drill core and mounted on an aluminium pin. The $2 \theta$ range covered by the detector was $12-92^{\circ}$, the corresponding $d$-space range 1.75-12.1 $\AA$. The number of 607 cradle positions were choosen in order to approximate an equal area scan. Additionally 96 cradle positions were used to cover the blind area $(6)$. The measuring time per point was approx. 120s (total time: 28h, which includes the movement of the cradle).

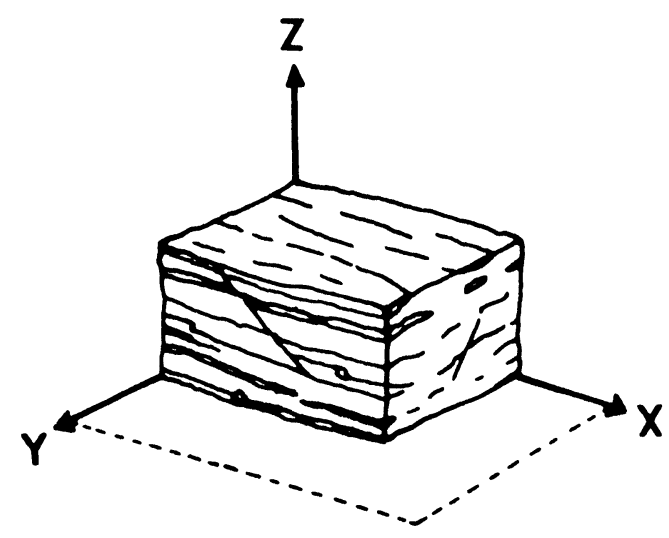

Fig. 1a: Relation between the rock sample and an orthogonal coordinate system: plane $\mathrm{XY}$ is parallel to the foliation plane; $X$ is oriented parallel to the macroscopic lineation.

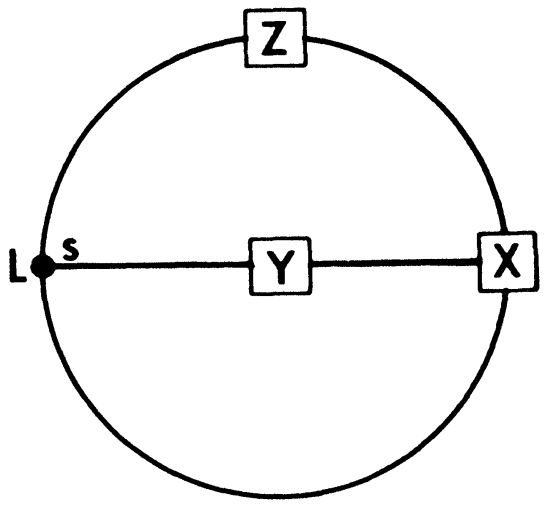

Fig. 1b: Relation between the rock sample and a pole figure using the orthogonal coordinate system.

s: trace of the foliation

L: lineation 


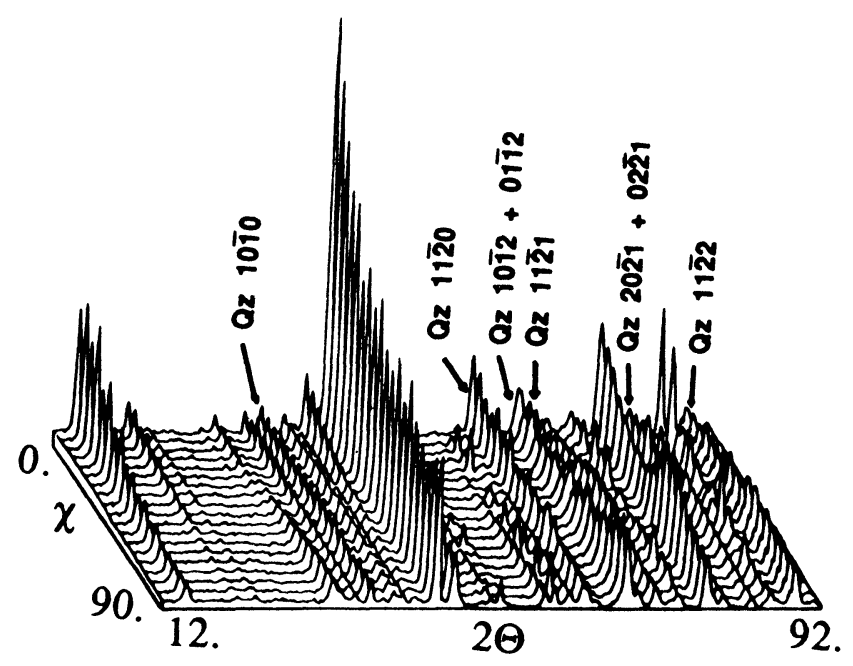

Fig. 2: Stack of diffraction spectra (specimen 71B5b) demonstrating the influence of the texture for $\phi=$ const; $\chi=0$ is parallel to direction $Z, \chi=90$ is parallel to direction $Y$ (cf. fig. 1). The quartz peaks used for ODF calculation are indicated.

\section{DATA TREATMENT}

The data produced by the D1B equipment consist of 20 spectra, one spectrum per cradle position. In figure 2 a stack of spectra demonstrates the texture qualitatively (cradle angle $\phi=$ constant). A large number pf peaks is present, which is due to the low crystallographic symmetry of oligoclase (tricline) and mica (biotite + muscovite: monocline). The problem of overlapping reflexions is well known. Several peaks belonging to one or a mixture of phases were separated by peak profile analysis(7). The quartz peaks used for further treatment are indicated in figure 2. Unfortunately, the quartz-(10-11+01-11) peak which is the strongest one in figure 2 cannot be separated from muscovite (006) and is not used.

A pole figure data set is produced from the separated data by calculating pole figure angles $\beta, \alpha$ from cradle angles $\phi, \chi$, taking into account the $\omega-\theta$ difference at the specific peak $(6)$. The view direction of the pole figures is towards the progressive drilling direction.

\section{ODF CALCULATION}

The ODF has been calculated using quartz pole figures (10-10),(1120), $(10-12+01-12),(11-21),(20-21+02-21)$ and $(11-22)$. The purely trigonal Bragg reflections $(|h| \neq|\mathbf{k}|)$ were divided in accordance to their structure 
factors $((10-12): 91 \%$ vs. $(01-12): 9 \%$ and $(20-21): 10 \%$ vs. $(02-21): 90 \%$, space group: $P 3_{1} 21$ (IT)). The complete ODF was calculated using the positivity condition $(8,9)$. The pole figures $(70-72),(16,30,-46,9),(04-43)$ and $(0001)$ were introduced during this procedure to minimize negative intensity values. The degree of series expansion was $L_{\max }=16$ because the contribution of higher degrees is negligtible. The complete ODF is presented in $2 \sigma$-sections $(10)$, the data of figure 5 are smoothened by an Gaussian function $\left(12.5^{\circ}\right)$ to accentuate the main structures.

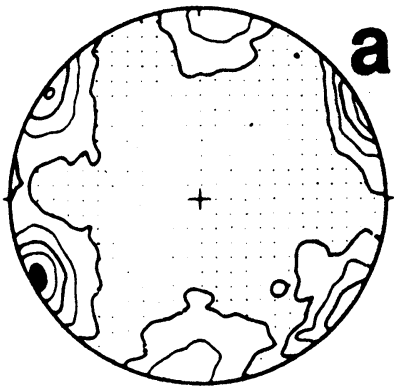

$11 \overline{2} 0$

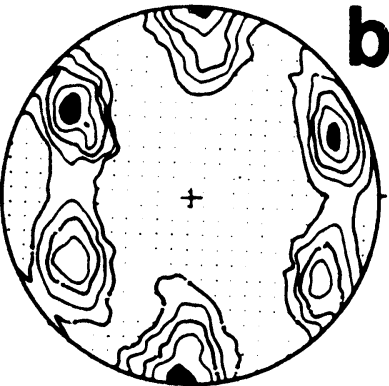

$11 \overline{2} 1$
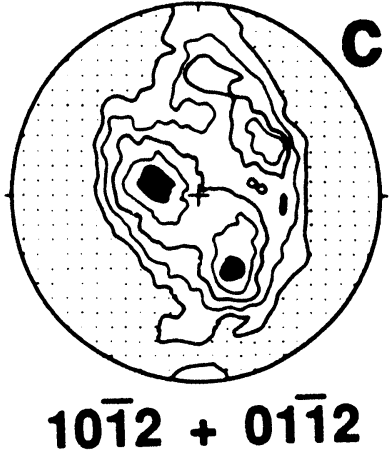
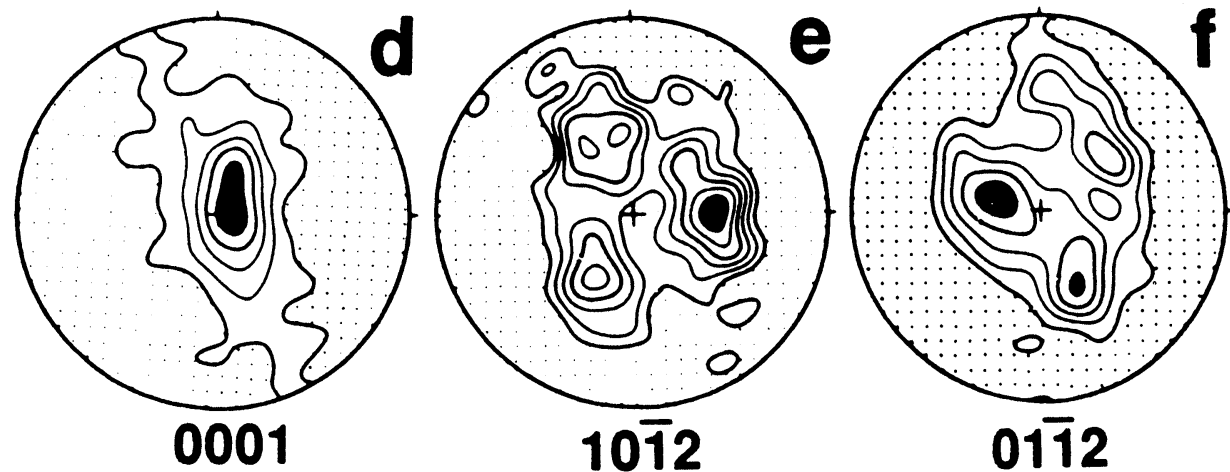

Fig. 3: Pole figures of specimen $71 \mathrm{~B} 5 \mathrm{~b}, \mathrm{a}-\mathrm{c}$ : measured, d-f: recalculated $\left(L_{\max }=16\right)$. Lambert Projection, lower hemisphere, all contour labels are multiples of random distribution. (a) $\min =0.32, \max =3.38$, steps: 1.0 , $1.5, \ldots .3 .0$; (b) $\min =0.40, \max =1.91$, steps: $1.0,1.2 \ldots, 1.8$; (c) $\min =0.24$, $\max =2.37$, steps:1.0,1.3,..,2.2; (d) $\min =-0.04$, $\max =5.75$, steps: $1.0,2.0, \ldots .5 .0$; (e) $\min =-0.02, \max =2.79$, steps: $1.0,1.3, \ldots, 2.5$; (f) $\min =0.24$, $\max =2.44$, steps: $1.0,1.3, \ldots, 2.2$; dotted: below 1.; black: above highest contour.

\section{DISCUSSION}

The quartz texture of specimen $71 \mathrm{~B} 5 \mathrm{~b}$ is considerably stronger than that of other specimens investigated. This is due to the influence of the ribbon quartz which contributes mainly to the quartz volume and the absence of younger quartz recrystallisation. The texture found produces very simple pictures (figure $3+5$ ) which are close to a single crystal orientation. Nevertheless there is some evidence of girdle distribution 

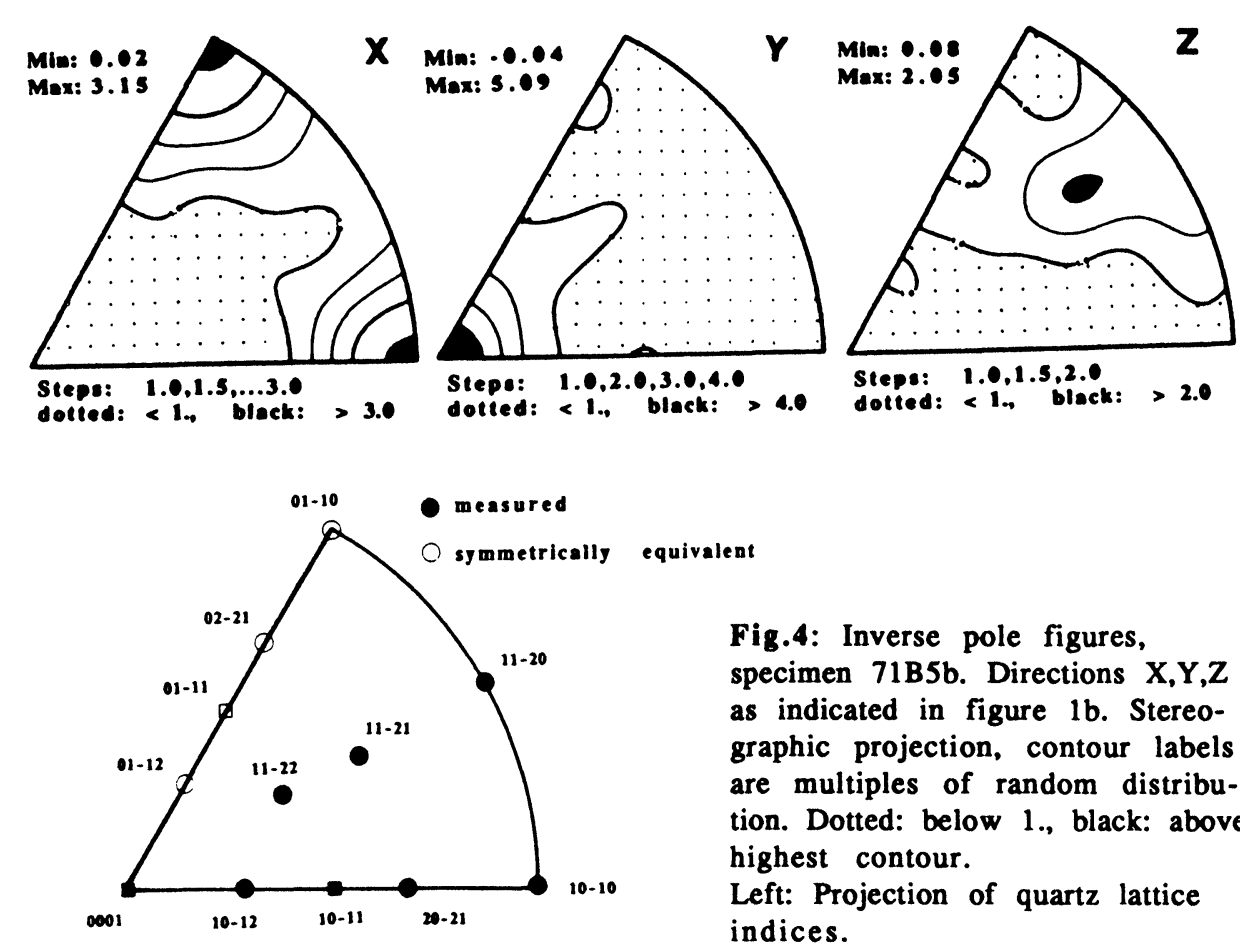

which is asymmetric with respect to the external coordinate system, indicating some portion of simple shear. This phenomenon is in accordance with other shear sense criteria (rotated clasts, shear band foliation)(4). The inverse polefigures (figure 4) exhibit the maximum (direction $Y$ ) whereas the girdle is not touched by directions $X$ and $Z$.

The quality of ODF calculation is demonstrated by comparision of measured and recalculated pole figures (figure 3 ). The asymmetric portion of the texture is reflected by the (11-20) and the (0001) pole figure. The comparision of $(11-21)$ and $(10-12+01-12)$ demonstrates the difference between a 'hexagonal' and a 'trigonal' pole figure. The measured pole figure of $(10-12+01-12)$ is dominated by (01-12) because of its higher structure factor.

In the ODF (figure 5) two elements of the quartz texture are remarkably distinct: the single girdle and the central maximum. This feature may be interpreted as a combination of two deformation types, propably ribbon vs. matrix quartz or older vs. younger grains.

\section{Acknowledgements}

Part of this work has been foundet by the German Research Foundation (DFG) under contract numbers BR961/1+2 and WE488/24. We are grateful to ILL, Grenoble and GKSS, Geesthacht for access to their facilities, respectively. 


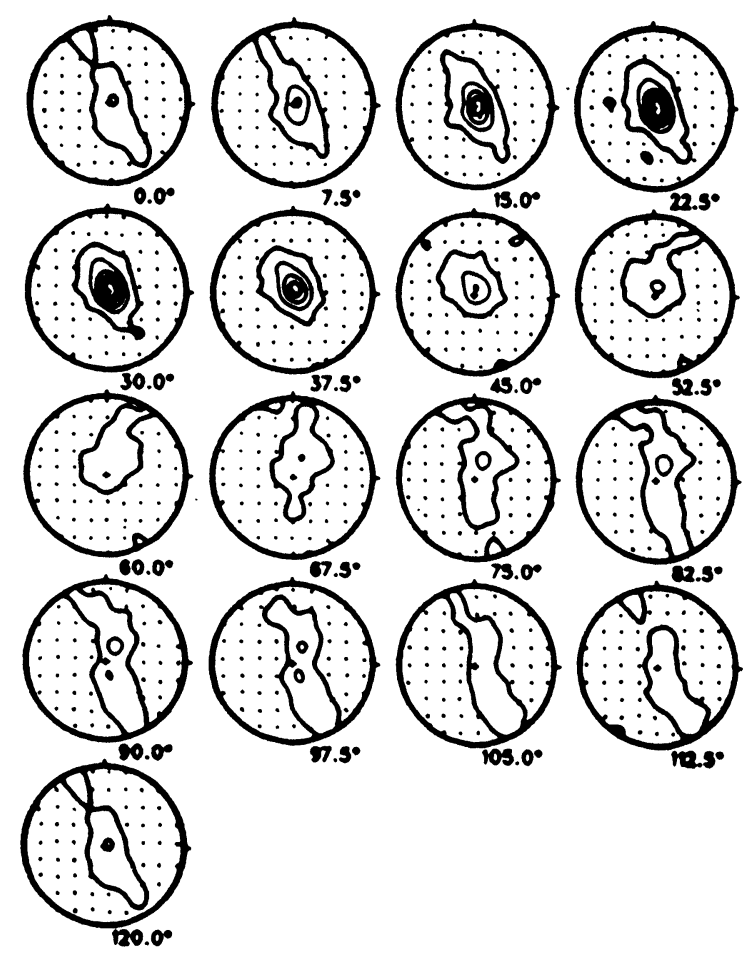

Fig. 5: Complete ODF of specimen 71B5b (2 $\sigma$-sections). The data have been smoothened by a Gaussian function $\left(12.5^{\circ}\right)$. Stereographic projection. $\min =-0.08, \max =10.41$, steps: $1 ., 3 ., 5 ., 7 ., 9 . ;$ dotted: below 1 .

\section{REFERENCES}

1. R. Emmermann and H. Rischmüller, GEOWEW 8,9,241-257 (1990)

2. A. Vollbrecht, K. Weber and J. Schmoll, Téctonophysics, 157,123-133 (1989)

3. H.-G. Brokmeier, F. Heinicke, H.J. Bunge and C. Ritter, KTB REPORT 89-3,408 (1989)

(The KTB Report is a periodical of the KTB project: KTB project magement, NLfB Hannover, Postfach 510153, D-3000 Hannover 51)

4. F. Heinicke and H. de Wall, KTB Report 90-? (in prep.)

5. H. Müller, M. Tapfer, R. Emmermann and W. Wimmenauer, KTB Report 89-3,61-66 (1989)

6. H.J. Bunge, H.R. Wenk and J. Pannetier, Textures and Microstructures, 5,153-170 (1982)

7. A. Filhol, J.-Y. Blanc, A. Antoniadis and J. Berruer: ABFfit for the Vax (Manual for the version 3.0), ILL 88FI05T, 77 p. (1988)

8. M. Dahms and H.J. Bunge, Textures and Microstructures,10,21-35 (1988)

9. M. Dahms and H.J. Bunge, J. Appl. Cryst.,22,439-447 (1989)

10. S. Matthies, K. Helmig and K. Kunze, phys. stat. sol. (b), 157,71-83 (1990) 